\title{
Analisa Patah Cover Body Sepeda Motor Menggunakan Simulasi Metode Elemen Hingga
}

\author{
Eko Saputra ${ }^{1, *}$, Rifky Ismail ${ }^{2}$, Jamari $^{2}$ \\ ${ }^{1}$ Jurusan Teknik Mesin Politeknik Negeri Semarang \\ Jl. Prof. Sudharto, SH., Tembalang-Semarang 50275, Telp.+6247473417 \\ ${ }^{2}$ Departemen Teknik Mesin, Fakultas Teknik, Universitas Diponegoro \\ Jl. Prof. Sudharto, SH., Tembalang-Semarang 50275, Telp. +62247460059 \\ *Email: eko.saputra@polines.ac.id
}

Diterima: 08-07-2021; Direvisi: 31-07-2021; Dipublikasi: 27-08-2021

\begin{abstract}
Abstrak
Cover body merupakan salah satu komponen sepeda motor yang berfungsi sebagai penutup rangka agar terlihat rapi dan sebagai pelindung bagian rangka dan kelistrikan dari kotoran maupun air. Cover body terbuat dari material polypropylene. Sebagian besar kerusakan yang terjadi pada cover body berupa fracture (patah). Tujuan dari paper ini adalah untuk mengetahui penyebab fracture pada cover body sepeda motor Suzuki Smash 110cc tahun pembuatan 2015. Dua metode analisa kegagalan yang digunakan adalah metode kaji literature dan metode elemen hingga dengan bantuan software FE ABAQUS. Hasil yang diperoleh dari kaji literatur adalah bahwa material polypropylene dapat mengalami kegagalan creep yang dipengaruhi akibat adanya fluktuatif temperatur dan adanya cyclic loading (fatigue), sedangkan hasil simulasi didapatkan letak lokasi konsentrasi tegangan yang terjadi akibat pembebanan statik sebagai pengganti cyclic loading. Kesimpulan dari penelitian ini adalah patah cover body disebabkan oleh perubahan fluktuatif temperatur dan adanya cyclic loading yang merupakan faktor penyebab kegagalan creep terhadap material polypropylene. Kombinasi antara creep dan konsentrasi tegangan akan menyebabkan initial crack yang kemudian terjadi proses crack propagation dan berakhir dengan terjadinya fracture.
\end{abstract}

Kata Kunci: crack propagation; creep; fracture; konsentrasi tegangan; polypropylene

\begin{abstract}
Cover body is one component of a motorcycle that functions as a cover frame to make it look neat and as a protector of the frame and electrical parts from dirt and water. Cover body is made of polypropylene material. Most of the damage that occurs to the cover body is in the form of fracture (broken). The purpose of this paper is to determine the cause of fracture in the cover body of a Suzuki Smash $110 \mathrm{cc}$ motorcycle in 2015. Two failure analysis methods used are the literature review method and the finite element method with the help of FE ABAQUS software. The results obtained from the literature review are that the polypropylene material can experience creep failure which is influenced by temperature fluctuations and the presence of cyclic loading (fatigue), while the simulation results show the location of stress concentrations that occur due to static loading as a substitute for cyclic loading. The conclusion of this study is that the cover body fracture is caused by changes in temperature fluctuations and the presence of cyclic loading which is a factor causing creep failure of polypropylene material. The combination of creep and stress concentration will cause an initial crack which then occurs in the process of crack propagation and ends with fracture.
\end{abstract}

Keywords: crack propagation; creep; fracture; polypropylene; stress concentration

\section{Pendahuluan}

Cover body sepeda motor mempunyai peranan yang penting untuk melindungi kerangka dari kotoran, air dan lumpur yang dapat merusak komponen kelistrikan. Pada tahun 1990-an, cover body dibuat dari pelat tipis dengan material logam sedangkan mulai tahun 1990-an material yang digunakan adalah polypropylene (PP) atau dalam kehidupan sehari-hari dikenal sebagai plastik. Polypropylene adalah salah satu jenis polimer yang paling sering digunakan dalam industri otomotif [1]. Meskipun material ini ringan, anti karat dan mudah dalam pembentukannya (bahasa latin; plasticus = mudah dibentuk), bukan berarti material ini bebas dari kerusakan atau kegagalan. Salah satu jenis kegagalan material polimer adalah terjadinya creep (mulur) bahkan pada suhu kamar [2]. Dapat dikatakan bahwa semua polimer akan mengalami creep sampai batas tertentu (waktu) yang kemudian dapat mengakibatkan initial crack dan sampai akhirnya terjadi 
Eko Saputra dkk /Jurnal Rekayasa Mesin

p-ISSN: 1411-6863, e-ISSN: 2540-7678

Vol.16|No.2|265-271|Agustus|2021

fracture (patah). Fracture dapat ditemukan pada beberapa cover body sepeda motor yang terbuat dari polypropylene, sebagai contoh dapat dilihat pada Gambar 1.
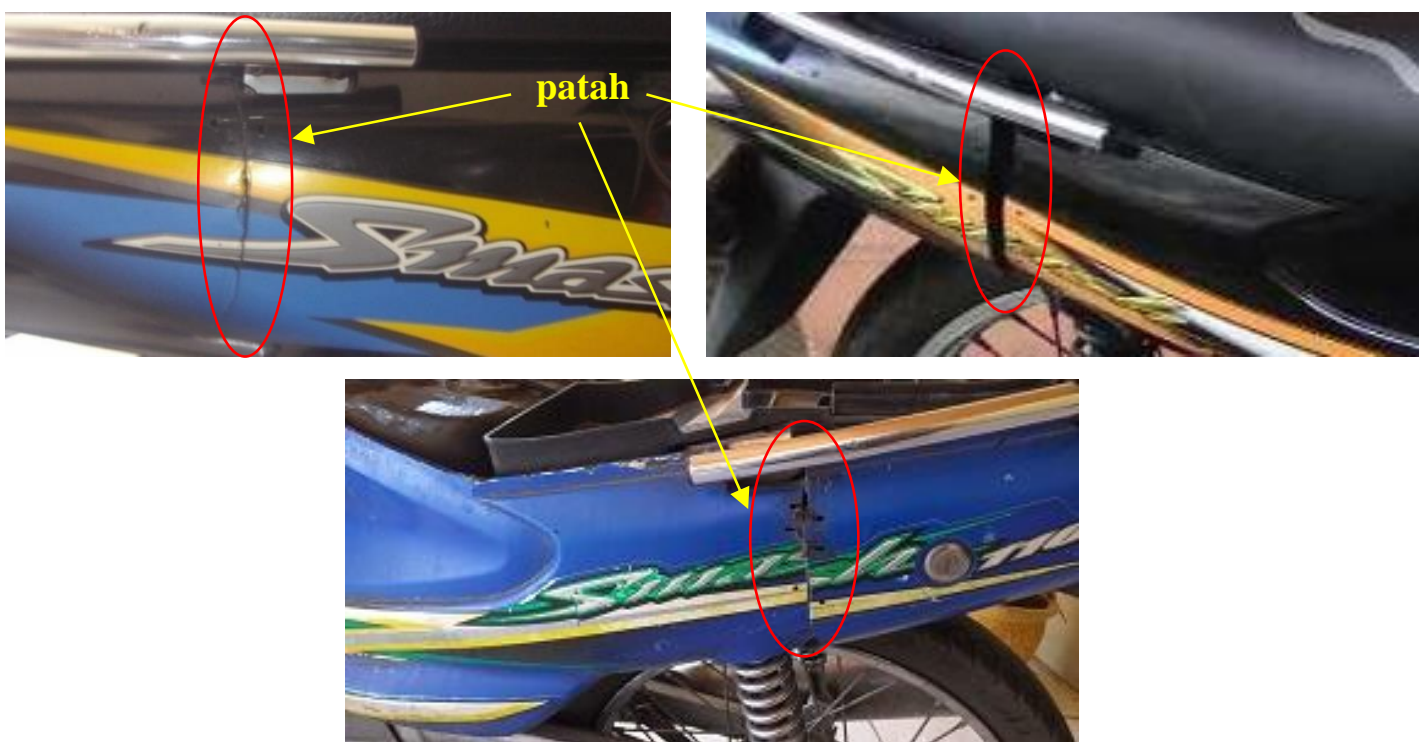

Gambar 1. Contoh cover body yang mengalami patah (fracture)

Creep dapat didefinisikan sebagai deformasi plastis (permanen) yang terjadi pada suhu tinggi di bawah beban konstan selama periode waktu yang lama [3]. Respon mekanik polimer ditentukan oleh perilaku intrisiknya (true stressstrain), yang bergantung pada struktur molekul, dan dipengaruhi oleh riwayat panas dan mekaniknya [4]. Selain itu, perbandingan tegangan-regangan terhadap waktu dapat dilihat pada Gambar 2 [5]. Kesimpulan informasi yang diperoleh dari literatur adalah bahwa kegagalan polimer dipengaruhi oleh temperatur dan beban konstan yang berlaku pada polimer tersebut. Banyak penelitian yang membahas tentang kegagalan creep pada polimer, misalnya; penelitian tentang hubungan creep sederhana untuk material polimer yang melibatkan pengaruh dari back stress [6]. Studi parametrik dari pengaruh-pengaruh cyclic loading terhadap sifat creep dari material polimer dan komposit yang berbasis polimer [7, 8, 9]. Analisa hubungan interaksi antara creep dan fatigue terhadap material polimer [10, 11]. Berdasarkan kajian pustaka tersebut, belum ditemukan penelitian yang membahas kegagalan plastik pada sepeda motor. Oleh karena itu, penelitian tentang kegagalan plastik pada sepeda motor sangat penting dilakukan. Dengan mengetahui jenis kegagalan plastik pada cover sepeda motor, diharapkan dapat ditemukan solusi untuk mengurangi kegagalan pada cover sepeda motor.

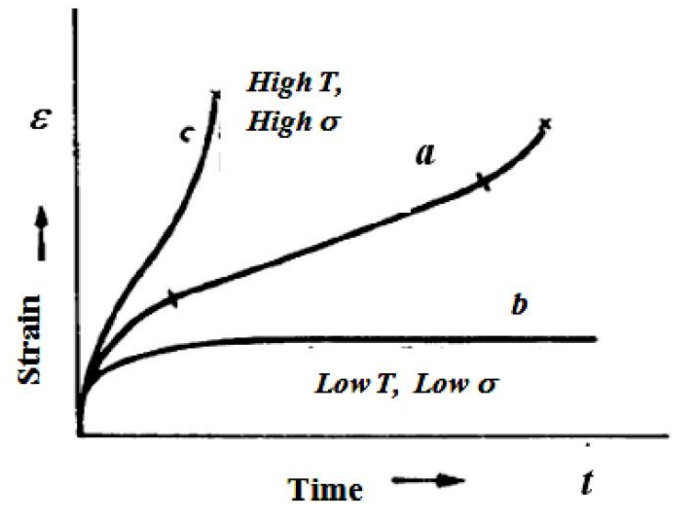

Gambar 2. Kurva creep pada polimer, diadaptasi dari Smallman dkk. [5] 
Tujuan penelitian ini adalah menganalisa penyebab fracture pada cover body sepeda motor Suzuki Smash 110cc tahun pembuatan 2005. Setelah dilakukan survey ternyata cover body sepeda motor tersebut hampir sebagian besar mengalami fracture dibagian samping, seperti terlihat pada Gambar 1. Metode analisa yang akan dilakukan adalah menggunakan metode kaji literatur dan metode elemen hingga dengan bantuan software finite element (FE) ABAQUS.

\section{Prosedur analisa kegagalan}

Patahnya (kegagalan) cover body pada sepeda motor Suzuki Smash 110cc tahun 2005 disebabkan oleh berbagai faktor. Kondisi operasi kerja sepeda motor sangatlah kompleks karena langsung berhubungan dengan medan jalan yang berbeda-beda baik halus (datar) maupun kasar (terjal). Oleh karena itu perlu dilakukan prosedur analisa kegagalan untuk mengetahui penyebabnya, untuk lebih jelas prosedur analisa dapat dilihat pada Gambar 3.

\subsection{Observasi patahnya cover body}

Pertama dimulai dengan observasi, untuk mencari data-data tentang patahnya cover body sepeda motor Suzuki Smash 110cc tahun pembuatan 2005. Observasi visual dilakukan pada tiga sepeda motor Suzuki Smash 110cc. Dari hasil observasi didapatkan data lokasi patah cover body yang sebagian besar berada pada daerah yang memiliki lekukan atau fillet seperti ditunjukkan dengan tanda panah pada Gambar 1, sedangkan material yang digunakan untuk cover body adalah jenis polypropylene.

\subsection{Prediksi kegagalan}

Kedua adalah prediksi kegagalan, dimana pada tahap ini dilakukan prediksi awal jenis kegagalan patah cover body tersebut, yaitu jenis kegagalan creep. Hal ini dapat terjadi karena adanya perubahan fluktuatif temperatur yang terjadi saat kondisi sepeda motor sedang parkir tanpa pelindung sehingga tersengat sinar matahari langsung. Kemudian karena adanya cyclic loading yang disebabkan oleh kondisi jalan yang tidak rata atau terjal dapat mengakibatkan getaran atau guncangan pada rangka dan cover body. Getaran atau guncangan ini diprediksi menjadi penyebab rusaknya bagian plastik yang terdapat pada baut pengunci yang berada pada bagian atas lampu belakang, dapat dilihat pada Gambar 4. Rusaknya bagian ini menyebabkan cover bagian belakang tidak terkunci sehingga posisi cover menjadi rentan untuk bergerak naik turun akibat getaran.

\subsection{Pembuktian prediksi kegagalan}

Ketiga adalah membuktikan prediksi kegagalan yang telah diutarakan pada tahap prediksi kegagalan. Ada dua kegiatan yang dilakukan, yaitu:

a. Membuktikan apakah jenis kegagalan creep dapat terjadi pada material polypropylene?. Hal ini dapat diketahui dengan percobaan-percobaan yang telah ada dalam literatur.

b. Dimana letak patah akan terjadi pada cover body?. Hal ini dapat diketahui dengan mencari letak konsentrasi tegangan yang terjadi pada cover body disaat kondisi cyclic loading. Dengan mengasumsikan getaran akibat kondisi jalan sebagai beban statis pada ujung belakang cover body maka dapat diketahui letak konsentrasi tegangan setelah disimulasikan menggunakan bantuan software FE ABAQUS, lebih jelas dapat dilihat pada Gambar 5. 
Eko Saputra dkk /Jurnal Rekayasa Mesin p-ISSN: 1411-6863, e-ISSN: 2540-7678

Vol.16|No.2|265-271|Agustus|2021

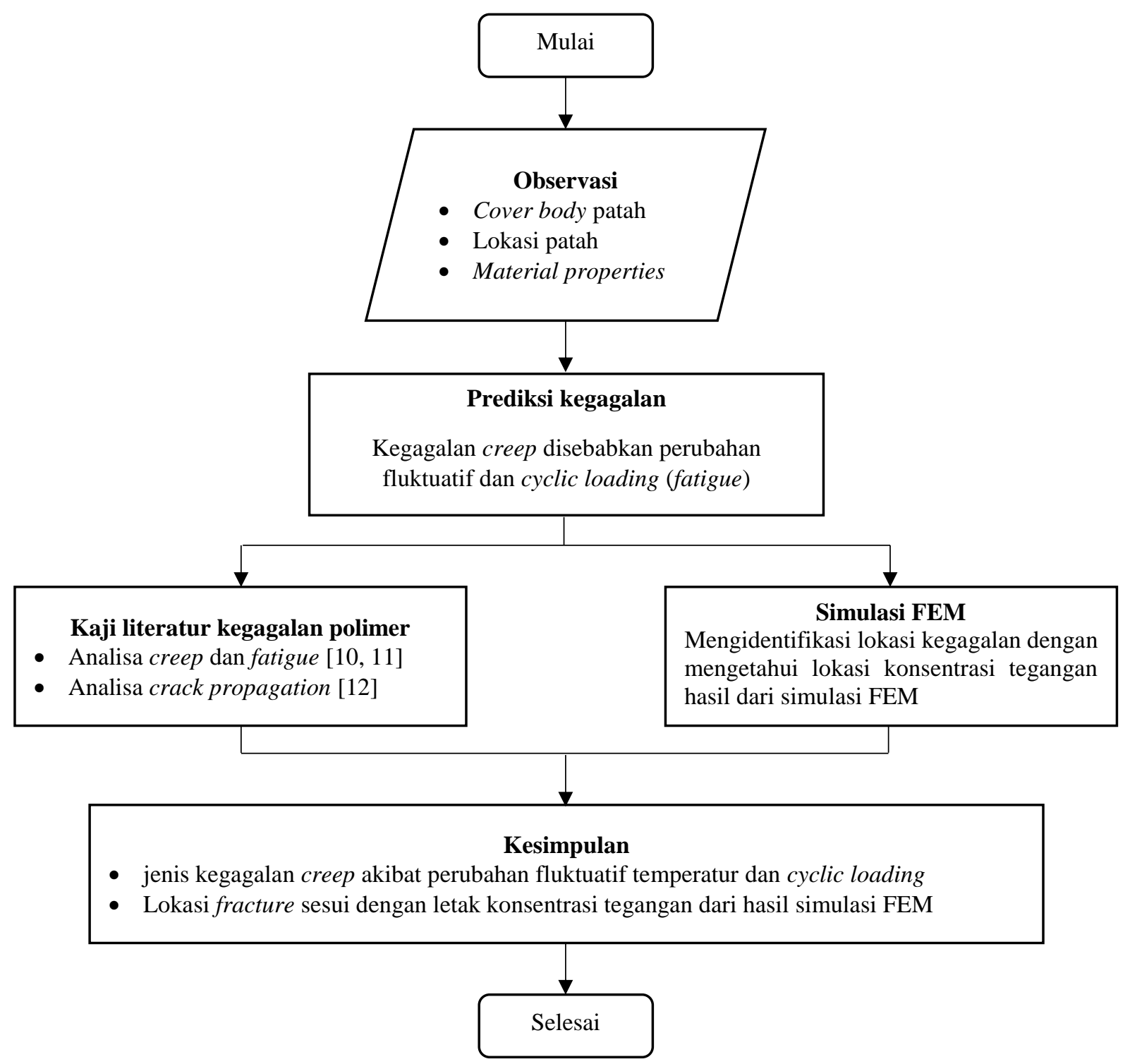

Gambar 3. Diagram alir prosedur analisa kegagalan

\subsection{Kesimpulan prediksi kegagalan}

Keempat adalah kesimpulan dari kaji literatur dan simulasi FEM yang telah dilakukan pada tahap pembuktian. Hasil dari kaji literatur menjelaskan jenis kegagalan yang mungkin terjadi pada material polypropylene, dan hasil dari simulasi FEM menjelaskan lokasi konsentrasi tegangan yang terjadi, kemudian dibandingkan dengan lokasi patah cover body sesungguhnya.

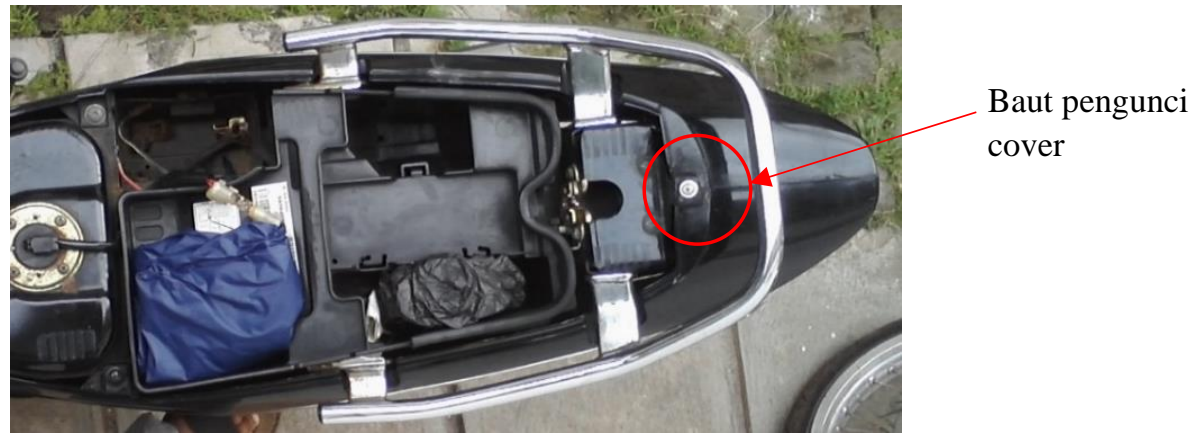

Gambar 4. Rusaknya plastik bagian baut pengunci cover 
Eko Saputra dkk /Jurnal Rekayasa Mesin

p-ISSN: 1411-6863, e-ISSN: 2540-7678

Vol.16|No.2|265-271|Agustus|2021

\section{Pemodelan FEM}

Pemodelan dilakukan dengan bantuan software FE ABAQUS. Model dibuat sedemikian rupa sesuai dengan bentuk cover body pada sepeda motor Suzuki Smash 110cc tahun 2005, informasi lebih jelas bisa dilihat pada Gambar 5. Model cover body dibuat dengan menggunakan CAD software. Analisa tegangan dilakukan menggunakan software metode elemen hingga yang dapat dilihat pada Gambar 6. Kondisi batas (constraint) diterapkan sesuai dengan posisi sekrup yang ditunjukkan dengan simbol huruf "C", dimana $\mathrm{C}$ adalah kondisi batas yang di terapkan agar derajat kebebasan ke segala arah tidak dapat bergerak. Beban statis terpusat disimbolkan dengan huruf "F", dimana nilainya adalah sesuai dengan gaya gravitasi $9.81 \mathrm{~N}$, pada kenyataan nilainya dapat berubah-ubah, namun fungsi pembebanan statis disini hanya untuk mengetahui lokasi konsentrasi tegangannya saja. Material yang digunakan adalah material polypropylene dengan modulus elastisitas $E=0.29 \mathrm{MPa}$ [13] dan ultimate strength $\sigma_{u}=36 \mathrm{MPa}$. Jenis elemen yang digunakan adalah tetrahedral [14] dengan jumlah elemen sekitar 150.000 elemen. Untuk mendapatkan kontur yang jelas maka dibagian yang menjadi prediksi adanya konsentrasi tegangan dapat dilakukan mesh (diskretisasi) yang lebih rapat atau halus.

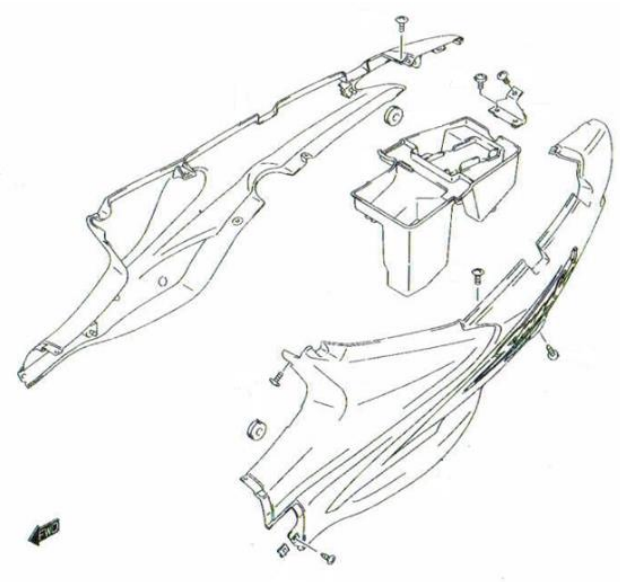

(a)

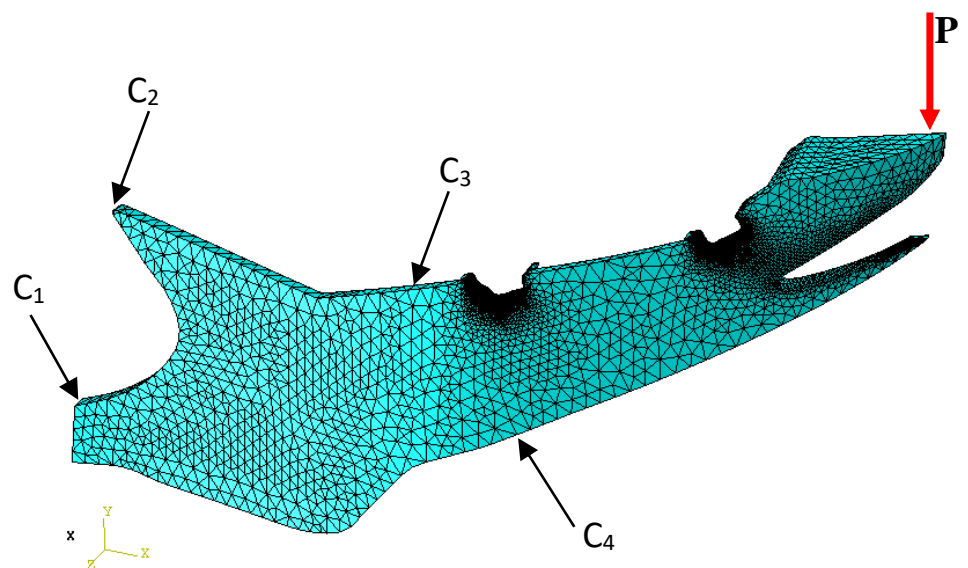

(b)

Gambar 5. (a) Frame cover sepeda motor suzuki smash FD 110 [15] dan

(b) model cover body dengan kondisi batas, pembebanan dan meshing

\section{Hasil dan pembahasan}

Setelah dilakukan analisa, patahnya cover body sepeda motor Suzuki Smash 110cc tahun 2005 disebabkan karena adanya kombinasi antara creep dan adanya konsentrasi tegangan. Creep terjadi karena dipengaruhi oleh dua faktor utama, yaitu pertama karena adanya temperatur yang cukup untuk terjadinya creep yaitu sekitar $30^{\circ} \mathrm{C}$ (creep dapat terjadi pada suhu kamar yaitu sekitar $293 \mathrm{~K}$ atau $20^{\circ} \mathrm{C}$ [2]) dan temperatur ini didapat saat kondisi sedang parkir (tersengat panas matahari langsung). Kedua karena adanya cyclic loading atau beban siklik (berulang-ulang) yang terjadi saat kondisi sepeda motor sedang melewati jalan kasar atau terjal. Karena pengaruh temperatur dan beban siklik terjadi secara terusmenerus, dalam jangka waktu yang cukup lama bergantung besarnya intensitas pengaruh tersebut (temperatur yang tinggi dan beban siklik yang tinggi), maka akan menyebabkan terjadinya initial crack (retak awal) dan lokasinya terjadi pada daerah konsentrasi tegangan. Setelah initial crack tercipta, sementara beban siklik masih terus berlangsung secara terus menerus maka selanjutnya terjadi proses crack propagation dimana akhirnya cover body tersebut terjadi fracture atau patah.

Lokasi konsentrasi tegangan dapat diketahui dengan melakukan simulasi menggunakan metode elemen hingga dan didapatkan hasil seperti pada Gambar 7. Tegangan von Mises yang terjadi pada simulasi ini masih dalam kondisi elastis. 
Eko Saputra dkk /Jurnal Rekayasa Mesin

p-ISSN: 1411-6863, e-ISSN: 2540-7678

Vol.16|No.2|265-271|Agustus|2021

Simulasi yang dilakukan tidak membahas tegangan luluh dan deformasi plastis karena fokus penelitian ini adalah lokasi konsentrasi tegangan akibat beban statis. Dapat terlihat kontur tegangan pada bagian cover body tersebut, dimana skala nilainya dapat dilihat pada legenda disampingnya. Dengan jelas bahwa lokasi terjadinya initial crack adalah seperti yang ditunjukkan dengan tanda panah, dan hal ini sesuai dengan kondisi fracture pada kenyataan.

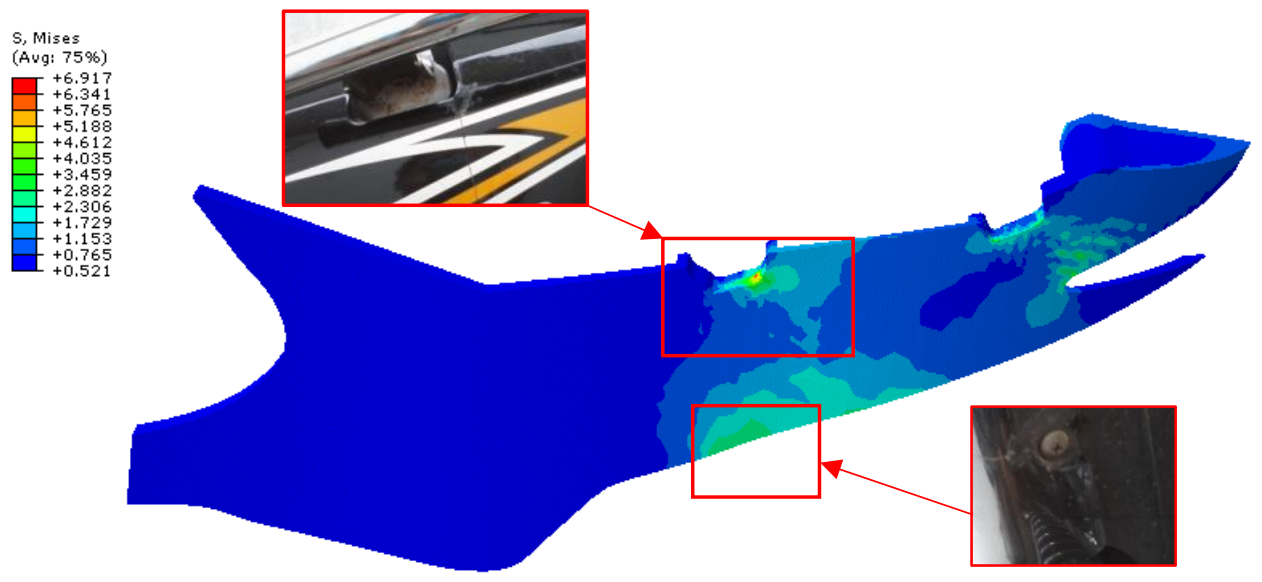

Gambar 7. Lokasi konsentrasi tegangan pada cover body sepeda motor dengan beban statis

\section{Kesimpulan}

Jenis kegagalan cover body (polypropylene) pada sepeda motor Suzuki Smash 110cc tahun 2005 adalah creep. Dua faktor utama yang mempengaruhi terjadinya creep pada polypropylene adalah adanya perubahan fluktuatif temperatur yaitu panas sengatan matahari saat parkir dan adanya cyclic loading (getaran atau hentakan disaat sepeda motor melewati jalanan yang kasar). Terjadi dalam jangka waktu tertentu dan berulang-ulang sehingga terjadi initial crack (pada daerah konsentrasi tegangan), kemudian terjadi proses crack propagation dan akhirnya terjadi fracture (patah). Metode elemen hingga dengan bantuan software FE ABAQUS digunakan untuk mengetahui letak konsentrasi tegangan pada cover body sepeda motor tersebut, dan hasilnya telah sesuai dengan kenyataannya.

\section{Referensi}

[1] Izer, A., Stocchi, A., Bárány, T., Pettarin, V., Bernal, C., Czigány, T., 2010, Effect of the consolidation degree on the fracture and failure behavior of self-reinforced polypropylene composites as assessed by acoustic emission. Polymer Engineering and Science, 50(11), 2106-2113. https://doi.org/10.1002/pen.21741

[2] Dropik, M.J., Johnson, D.H., Roth, D.E., 2003, Developing an Ansys creep model for polypropylene from experimental data, Penn State-Erie, Erie, PA, USA

[3] Shackelfor, J.F., 2005, Introduction to materials for engineers, sixth edition, Pearson Education, Inc., Upper Saddle River, NJ.

[4] Klompen, E.T.J., 2005, Mechanical properties of solid polymers: constitutive modelling of long and short term behaviour Eindhoven: Technische Universiteit Eindhoven DOI: 10.6100/IR583394

[5] Smallman, R.E., Bishop, R.J., 2006, Metalurgi Fisik Modern dan Rekayasa Material, Ed. 6, Penerbit Erlangga, Jakarta, Indonesia.

[6] Nishitani, T., Tsuji, M., Suetsugu, M., Ogura, H., 1995, Simple creep relation for a polymer that includes the effect of back stress, The Journal of Strain Analysis for Engineering Design, Vol. 30, No. 1, Hal. 79-81 
Eko Saputra dkk /Jurnal Rekayasa Mesin p-ISSN: 1411-6863, e-ISSN: 2540-7678

Vol.16|No.2|265-271|Agustus|2021

[7] Schumacher, S.C., 2000, Parametric study of cyclic loading effects on the creep behavior of polymers and polimer based composites, MS Dissertation, Montana State University, Bozeman.

[8] G. Spathis, E. Kontou, Modeling of viscoplastic cyclic loading behavior of polymers, Mech Time-Depend Mater (2015) 19:439-453

[9] Erasmo Correa Gómez, Gonzalo M. Domínguez Almaraz, Julio C. Verduzco Juárez, Crack initiation and propagation on CT specimens of two polymers (ABS and PMMA), under cyclic constant displacement loading, Theoretical and Applied Fracture Mechanics, Volume 100, 2019, hal. 55-64, https://doi.org/10.1016/j.tafmec.2018.12.013.

[10] Vinogradov, A.M., 2001, creep-fatigue interaction in polymers, Department of Mechanical and Industrial engineering, Montana State University, Bozeman, MT, 59719.

[11] Eftekhari, M., Fatemi, A., Creep-Fatigue Interaction and Thermo-Mechanical Fatigue Behaviors of Thermoplastics and Their Composites, International Journal of Fatigue (2016), doi: http://dx.doi.org/10.1016/j.ijfatigue.2016.05.031

[12] Dear, J.P., Ibru, P.A., 1993, Steady state crackpropagation in small specimens of polymers of varying toughness, Polymer testing, Vol. 12, No. 1, Hal. 79-92

[13] http://www.engineeringtoolbox.com/young-modulus-d_417.html diakses 07 Juli 2021.

[14] ABAQUS (2012) Analysis User's Manual. Version 6.12, Dassault Systemes Simulia, Inc.

[15] https://www.suzuki.co.id/eparts/smash-fd-110-xcd/body/figure/21508 diakses 07 Juli 2021 